\title{
Time for Change in the Conduct of Clinical Trials in Patients with Rheumatoid Arthritis
}

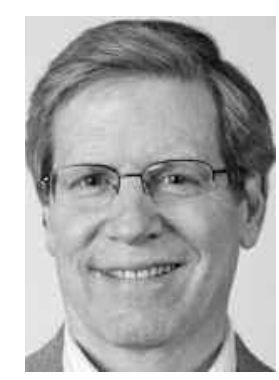

What science can there be in a matter in which, as in all practical matters, nothing can be defined and everything depends on innumerable conditions, the significance of which is determined at a particular moment which arrives no one knows when?

Prince Andrew, War and Peace, Leo Tolstoy

Doing clinical research in rheumatology has never been easy. There really wasn't much going on 30 years ago and a "clinical trialist" was challenged to find something to study. Then came methotrexate (MTX), and for more than 20 years trials of its efficacy, safety, tolerability, pharmacokinetics, and mechanism of action dominated the scene. It's difficult for young clinical investigators to appreciate a therapeutic epoch that was so entirely dominated by a single drug. Back then, many were frightened by MTX and those misgivings were often transferred to patients as well as other physicians and pharmacists. We really weren't very sure about this drug.

The present clinical climate could not be more different. Nine new biologic drugs have been approved in the United States in the last 13 years, and several other new agents are almost there. While this is definitely good for patients, it has become challenging to remain an ethical trialist while succeeding in North America. That is, if a patient has insurance and can access a variety of new drugs, why would they want to participate in a study of an unproven agent in which they might get nothing more than a sugar pill? By definition, the patient's disease is active and they understandably want relief now, not in 3 or 4 months. (Could my rheumatologist really have my own interest at heart when she/he enters me in a trial with a placebo, if my insurance will pay for approved drugs?) And how does an ethical clinician get patients to participate, unless they have no other options because of insurance issues?

Add to the above the situation of artificially high disease activity criteria not representative of the population in which the drug will eventually be marketed. While there is movement to include an active, approved comparator agent in newer trials, pharmaceutical companies must still include a placebo control arm at some point in phase II and III clinical trials. A minimum level of active disease is defined so that the results can be compared with drugs already in the marketplace that were studied and approved using similar criteria. Of course, if subjects with too little disease activity are allowed to enter, there would be a well-described "floor effect" in which the efficacy of any intervention would become more difficult to demonstrate when starting with disease that is simply doing too well compared with prior study entry requirements.

It must be observed that uniformity of regulatory standards can be a virtue, but does not necessarily work if the characteristics of the patient population have changed over the course of a relatively short timeframe. And this is actually the case in trials of patients with RA.

In this issue of The Journal, Karsh and colleagues present a series of recommendations for much-needed changes in the conduct of clinical trials in patients with $\mathrm{RA}^{1}$. Developed in a modified group consensus format by the Canadian Rheumatology Research Consortium (CCRC), the authors do a superb job of identifying the many issues associated with clinical trial conduct in a world of very different and continuously evolving regional and geographic clinical circumstances. The authors offer some watershed recommendations that deserve serious discussion in a variety of different venues.

The authors note the difficulty of finding patients who are representative of the kinds of individuals who will actually receive the study drug once it is approved. Finding these subjects in North America at this time is more of a challenge than convincing patients in the 1980s that MTX was relatively safe and effective. In the Canadian Early Arthritis Cohort (CATCH) of 886 patients there was a mean swollen 28-joint count of 3.7 (SD 5.5) and tender joint count of 4.4 (SD 4.5) at 12 weeks from the initial consult ${ }^{1}$. In the US, the CORRONA registry found a mean joint count of 2.9 (SD 5.1) tender and 2.7 (4.2) swollen joints in patients with established disease ${ }^{2}$.

See Canadian recommendations for RA clinical trials, page 2095

Personal non-commercial use only. The Journal of Rheumatology Copyright (C 2011. All rights reserved. 
But this is not the case in other areas of the world where pharmaceutical manufacturers are compelled to go in order to more easily enroll patients with the traditional 6 tender and 6 swollen joint counts along with elevated acute-phase reactants. It is now estimated that approximately $50 \%$ of the patients treated in the United States have received biologic agents. This compared with approximately $8 \%$ in the United Kingdom and low single digits in Latin America, Central and Eastern Europe, and $\mathrm{Asia}^{3}$. If you were a director of a pharmaceutical company that had invested tens of millions of dollars in developing a drug, where would you go to perform studies? Where it was easy because of less competition from approved agents? Or where it was expensive and difficult to find appropriate subjects because of intense competition from the penetration of multiple new agents in the study population?

And, yes, as Karsh, et al state, there are ethical issues associated with studying a drug that will probably not become available in the population used for the trial. The results of these investigations are then applied to subjects who are from a markedly different population, with distinct sociodemographic differences, and access to numerous new drugs, with resultant lesser disease activity ${ }^{2,4}$.

The elephant in the room is the regulatory agencies that seem to cling stubbornly to outdated requirements for disease activity. That is, it may be inappropriate to cast aspersions at the pharmaceutical industry if they are being forced to jump through certain outmoded hoops. It's just easier to go to areas of the world where access to new and expensive drugs is uncommon, where patients who meet entry criteria required by regulatory agencies abound so that results of the test drug can be compared with its predecessors. One of the unfortunate, but understandable, spinoffs of the globalization of trials and the proliferation of new drugs in the US is the lament now heard among some North American trialists: "My research unit is dying!"

But wait. Can it be right to cast all the blame on outmoded regulation? These people work hard and are undoubtedly trying to be proactive with insufficient resources.
Karsh and colleagues at CCRC have performed a huge service by so adroitly identifying the challenges. Their suggested solutions include liberalizing entry criteria to new studies to a Disease Activity Score 28 of $>3.2$, plus $>3$ tender and $>3$ swollen joints, and an elevated acute-phase reactant, either an erythrocyte sedimentation rate or C-reactive protein. These changes would certainly lead to enhanced enrollment in North America and consequently better representation from the populations where the drugs being tested are likely to be used.

These thresholds will rightly be debated and it is likely that a dialogue will ensue. But the authors have become eloquent advocates of sorely needed change in a challenging and evolving landscape.

JOEL M. KREMER, MD, The Center for Rheumatology, 1367 Washington, Avenue, Albany, New York 12206, USA

Address correspondence to Dr. Kremer.E-mail: jkremer@joint-docs.com

\section{REFERENCES}

1. Karsh J, Keystone EC, Haraoui B, Thorne JC, Pope JE, Bykerk VP, et al. Canadian recommendations for clinical trials of pharmacologic interventions in rheumatoid arthritis: inclusion criteria and study design. J Rheumatol 2011;38:2095-2104.

2. CORRONA US RA Disease Registry. [Internet. Accessed May 26, 2011.] Available from: http://www.corrona.org/i/index.html

3. Curtis JR, Jain A, Askling J, Bridges SL Jr, Camona L, Dixon W, et al. A comparison of patient characteristics and outcomes in selected patients followed in a large U.S. disease registry. Semin Arthritis Rheum 2010;40:2-14.

4. Glickman SW, McHutchison JG, Peterson ED, Cairns CB, Harrington RA, Califf RM, et al. Ethical and scientific implications of the globalization of clinical research. N Engl J Med 2009;360:816-23.

J Rheumatol 2011;38:2087-8; doi:10.3899/jrheum.110656 